\title{
Turbine design and analysis for the J-2X Engine turbopumps
}

\author{
Bogdan Marcu ${ }^{1}$ and Ken Tran ${ }^{2}$ \\ Pratt \& Whitney Rocketdyne, Canoga Park, CA, 91309 \\ Daniel J. Dorney ${ }^{3}$ and Preston Schmauch ${ }^{4}$ \\ NASA Marshall Space Flight Center, Huntsville, AL
}

Pratt and Whitney Rocketdyne and NASA Marshall Space Flight Center are developing the advanced upper stage $J-2 X$ engine based on the legacy design of the $J-2 / J-2 S$ family of engines which powered the Apollo missions. The cryogenic propellant turbopumps have been denoted as Mark72-F and Mark72-O for the fuel and oxidizer side, respectively. Special attention is focused on preserving the essential flight-proven design features while adapting the design to the new turbopump configuration. Advanced 3-D CFD analysis has been employed to verify turbine aero performance at current flow regime boundary conditions and to mitigate risks associated with stresses. A limited amount of redesign and overall configuration modifications allow for a robust design with performance level matching or exceeding requirement.

\section{Introduction}

$\mathrm{T}$ he J-2X engine is planned to power the Ares-I crew launch vehicle's upper stage and the Earth departure stage of the Ares-V cargo launch vehicle. Building on the flight-proven heritage of the Apollo J-2 engines, the J-2X is a gas generator cycle engine employing a fuel and an oxidizer turbopump whose turbines are configured in series, with the fuel turbine upstream of the oxidizer turbine. The utilization of the flight-proven J-2 and heritage J-2S turbopump designs allows for a significant reduction in the development schedule, costs and risks. Originally designed in the 1960 's, the turbopumps are being refurbished to operate at a higher thrust level of $294,000 \mathrm{lbf}$ by employing new, state of the art modeling and analysis tools to insure an exceptional level of safety and flawless operation during the planned space missions. Figure 1 and Figure 2 show comparisons of the two turbopump designs side by side, the heritage Apollo era design and current design.

The present report addresses the necessary design changes and the analysis carried for the J-2X turbines which have been denoted as Mark72-F and Mark72-O for the fuel and oxidizer sides, respectively. Pratt and Whitney Rocketdyne's (PWR) turbopump design team has applied the first-time-through design process demonstrated on the MBXX Demonstrator Engine Fuel Turbopump [1,2] operating jointly with the NASA Marshall Flight Space Center (MSFC) team in an efficient and synergistic manner. This paper will present and discuss 3-D unsteady CFD results obtained by the MSFC team employing the Phantom CFD analysis code which was run at the NASA Advanced Supercomputing Division center at Moffet Field, California. Aerodynamic loading obtained from the CFD analysis have been analyzed for turbine performance by the Pratt and Whitney Rocketdyne (PWR) aerodynamic analysis team, while steady and unsteady pressure data from the CFD solution have been applied on the ANSYS structural models for stress and High Cycle Fatigue (HCF) analysis at PWR.

\section{Numerical Procedure for $\mathbf{J}-2 \mathrm{X}$ turbines aerodynamic analysis}

The code used to perform the simulations is PHANTOM, a code developed at NASA Marshall Space Flight Center. The governing equations in the PHANTOM code are the three-dimensional, unsteady, Navier-Stokes equations. The equations have been written in the Generalized Equation Set format, enabling it to be used for both

\footnotetext{
${ }^{1}$ Principal Engineer, Ph.D., Senior AIAA Member

${ }^{2}$ Principal Engineer

${ }^{3}$ Team Leader, Associate Fellow AIAA

${ }^{4}$ Aerospace Engineer
} 
liquids and gases at operating conditions ranging from incompressible to supersonic flow [3]. The code employs a system of overset O-grids and $\mathrm{H}$-grids to discretize the flow field. The grids move to simulate blade motion. A modified Baldwin-Lomax turbulence model is used for turbulence closure [4]. The code contains two options for the fluid properties. The first option is based on the equations of state, thermodynamic departure functions and corresponding state principles constructed by Oefelein [5]. The second option is based on splines generated from the NIST Tables [6]. Message Passing Interface (MPI) protocols are used for parallel simulations. A detailed description of the code/algorithm development, as well as its application to several turbine and pump test cases, is presented in Refs. 3 and 7.

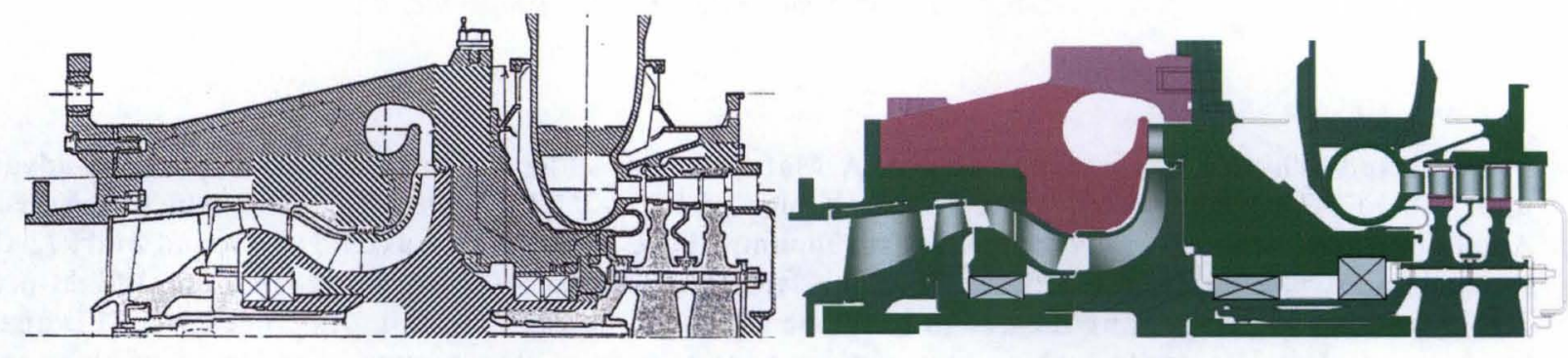

Figure 1. Baseline J-2 and current J-2X fuel turbopump
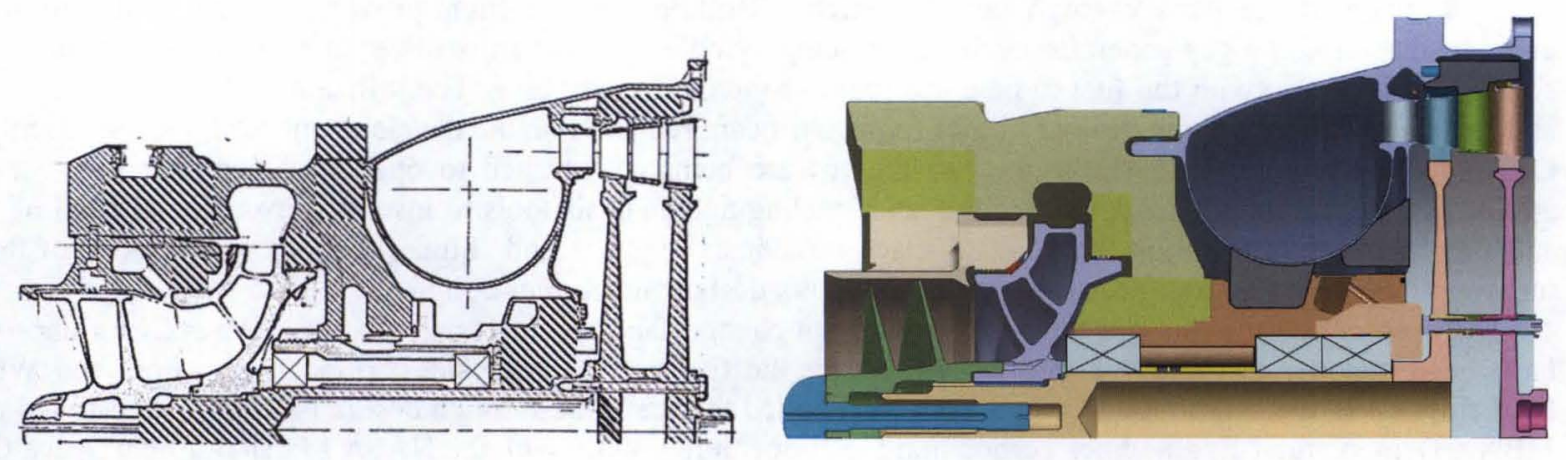

Figure 2. Baseline J-2 and current J-2X oxidizer turbopump

\section{The J-2X Fuel Turbine Mark72-F}

\section{A. General configuration}

The heritage J-2S fuel turbine is a two stage impulse supersonic turbine with most of the pressure drop occurring in the 1st vane producing supersonic Mach numbers at the $1^{\text {st }}$ vane exit. The flow is accelerated in the nozzle vane to high supersonic Mach levels through a convergent-divergent channel resulting in supersonic regime even in the rotating reference frame of the $1^{\text {st }}$ blade. The nozzle discharges at $19.5^{\circ}$ angle and 1.18 Mach on the 1st blade relative frame as set by the geometry of the $1^{\text {st }}$ blade leading edge through the "Unique Incidence" theory [8] relating incidence to inlet Mach number. A summary of the turbine operating parameters at $294 \mathrm{~K}$ thrust level is documented in Table 1. 


$\begin{array}{ll}\text { Pressure ratio } & 6.00 \\ \text { RPM } & 30000 \\ \text { U/Co } & 0.186 \\ \text { Mean Diameter (in) } & 10.5\end{array}$

Table 1: 294K lbf thrust operating point of the fuel turbine.

The new $\mathrm{J}-2 \mathrm{X}$ fuel turbine flow path is illustrated in Figure 3. The turbine is almost identical to the heritage design except for the 1st nozzle vanes. The latter are modified to enhance structural margin of the 1st rotor blades. The 1st vane number is changed from 34 to 37 to prevent a near resonant interference with the blade torsional mode in the Campbell diagram (Figure 4). In addition, the heritage radially stacked vanes are leaned to minimize the dynamic load on the vane trailing edge. In fact, structural forced response analyses indicate that the interaction between the supersonic flow at the exit of the vane and the 1st rotor blade is very strong producing quite high levels of alternating stresses on 1 st blade and on the 1 st vane trailing edge. The 1 st vane is leaned by $20^{\circ}$ against the direction of rotation based on CFD optimization.

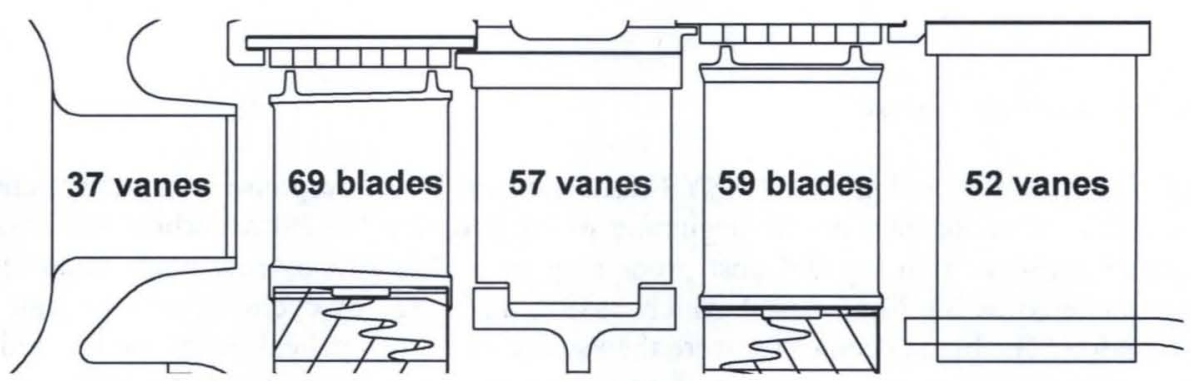

Figure 3. The J-2X Mark $72-\mathrm{F}$ turbine flow path 


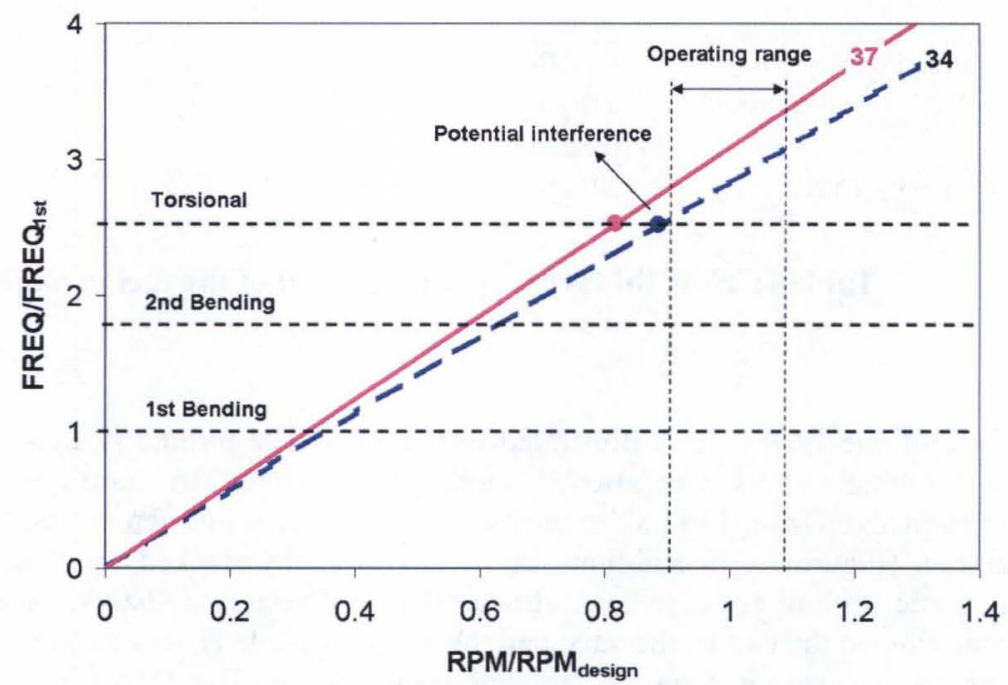

Figure 4. J-2X Mark $72-\mathrm{F}$ fuel turbine $1^{\text {st }}$ rotor Campbell Diagram

\section{B. J-2X Fuel turbine analyses}

The 3D Phantom code coupled with ANSYS finite element forced response analyses are employed to insure the reliability of turbine components. At the beginning of the program the entire turbine was modeled using cyclical sector models to conserve running and post processing time. The row-by-row blade count of 37-69-57-59-52 in Figure 3 was modeled as 35-70-56-63-49 which, taking advantage of cyclic symmetry, can be reduced to a pie sector of 5-10-8-9-7. The blade geometries were then scaled to fit the cyclical sector model. Although this procedure was found to be adequate for aerodynamic performance predictions, it was found through further investigations [9] that "scaling" is not accurate enough for structural forced response analyses because of the phase difference in local unsteady pressures acting on the blade surface. Therefore, the turbine was to be modeled with the true blade ratios meaning, in this particular case of prime numbers of blades, a full $360^{\circ} \mathrm{CFD}$ model approximately 7 times larger in grid size. 


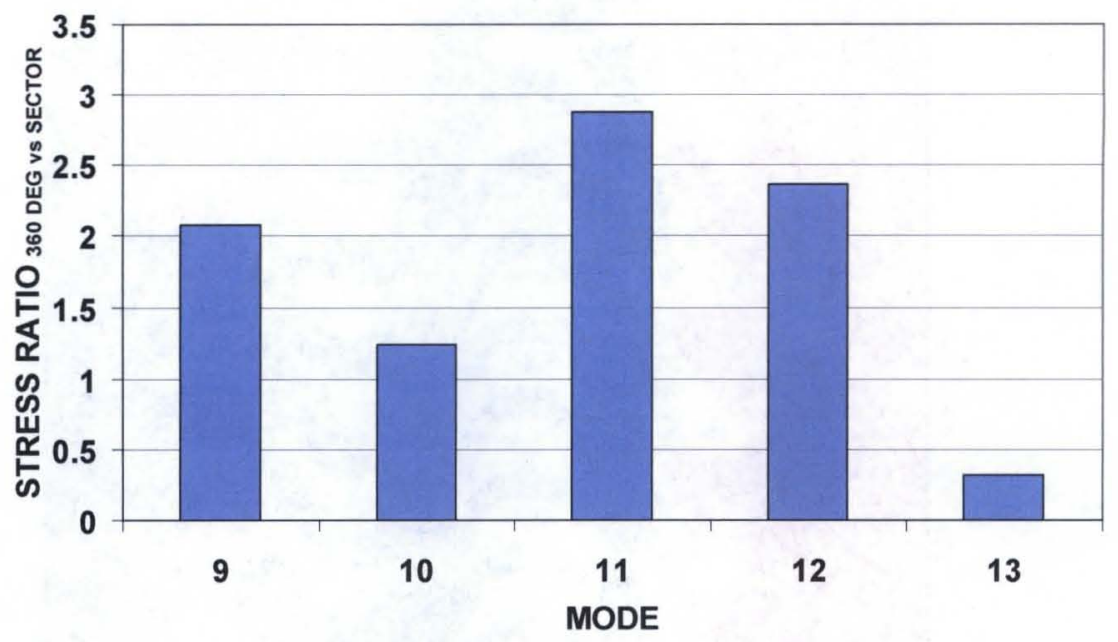

Figure 5. J-2X Mark72-F Fuel Turbine $1^{\text {st }}$ blade alternating stress due to $1^{\text {st }}$ vane excitation. Shown is the ratio between the stress calculated based on a scaled grid CFD solution and the stress calculated based on full annulus un-scaled CFD solution

Figure 5 documents the forced response analysis results for the $1^{\text {st }}$ blade. The $360^{\circ}$ model shows higher alternating stresses for mode $9,10,11$ and 12 but lower for mode 13 .

A section of the computational grid used in the fluid simulations is shown in Figure 6. The complete grid system contained in excess of 56 million grid points. The simulations were run on between 128 and 176 processors of an Altix cluster located at NASA Ames Research Center.

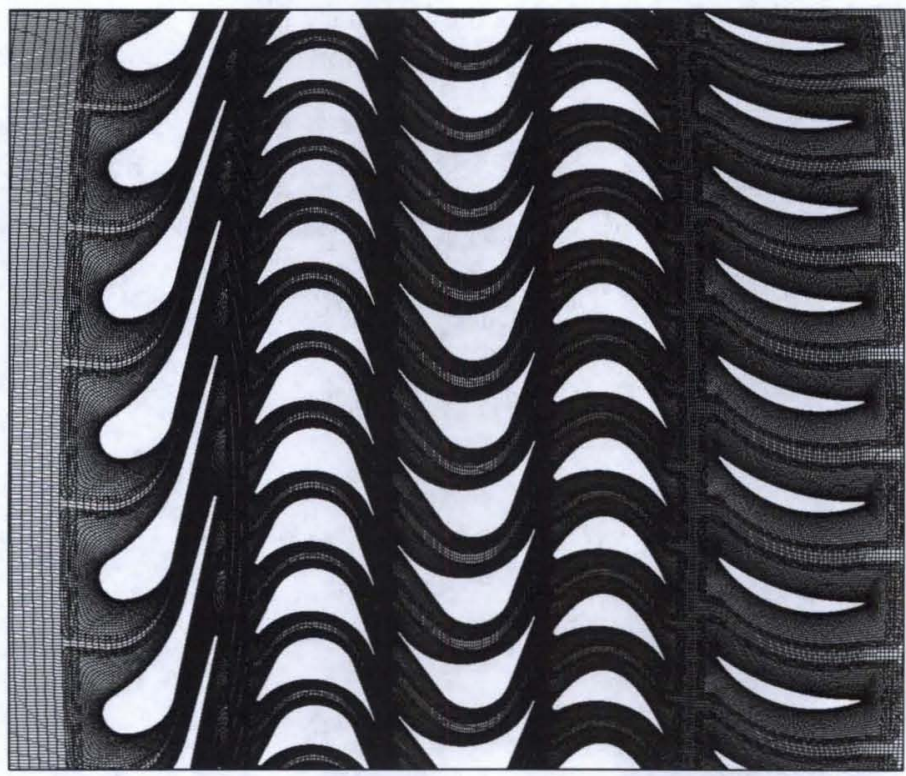

Figure 6. Computational grid for the J-2X Mark72-F fuel turbine

Figure 7 shows instantaneous static pressure contours at midspan of the turbine. Characteristic of most supersonic turbines, the largest pressure drop occurs across the nozzle, with relative constant pressure observed in the first-stage rotor and second stage of the turbine. 


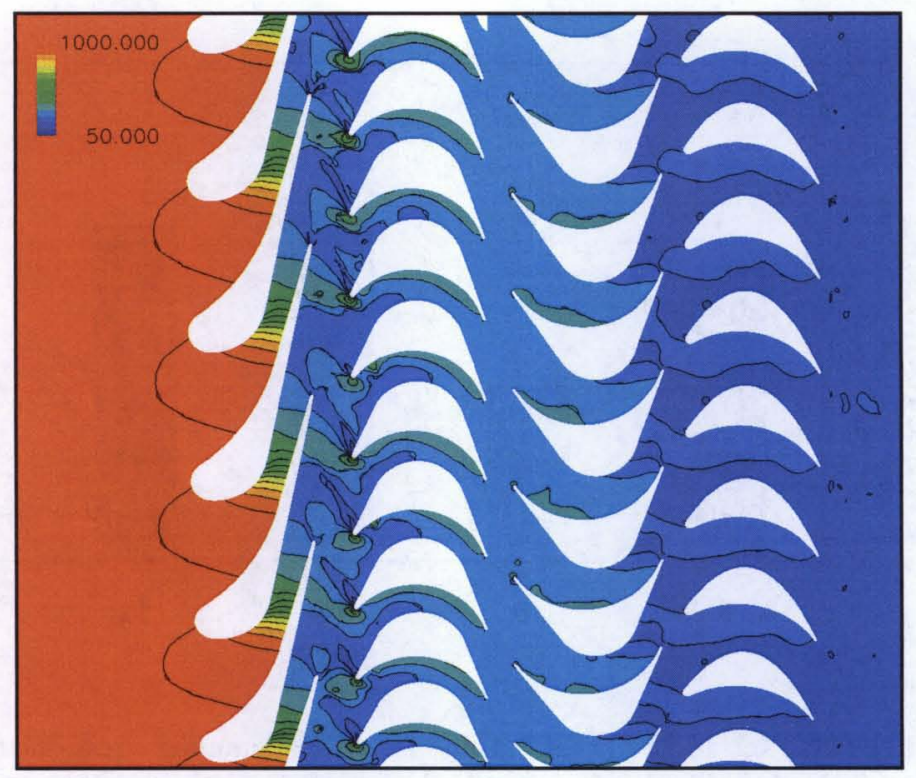

Figure 7. Static pressure (psi) at midspan of the J-2X Mark72-F fuel turbine

The relative frame Mach number at midspan of the turbine is shown in Figure 8 . This figure highlights both the supersonic flow regions, as well as the regions of high loss (e.g., separated flow regions). A complex flow structure is observed between the nozzle and first-stage rotor. Some of the dominant features include: i) expansion waves emanating from the trailing edge of the nozzle which reflect off the suction surface of the adjacent nozzle and interact with the nozzle wake further downstream, ii) a strong bow shock in front of the first-stage rotor which impacts the suction surface of the adjacent rotor (causing the boundary layer to separate) and interacts with the wake and reflected expansion wave from the nozzle, and iii) flow separation on the second-stage rotor.

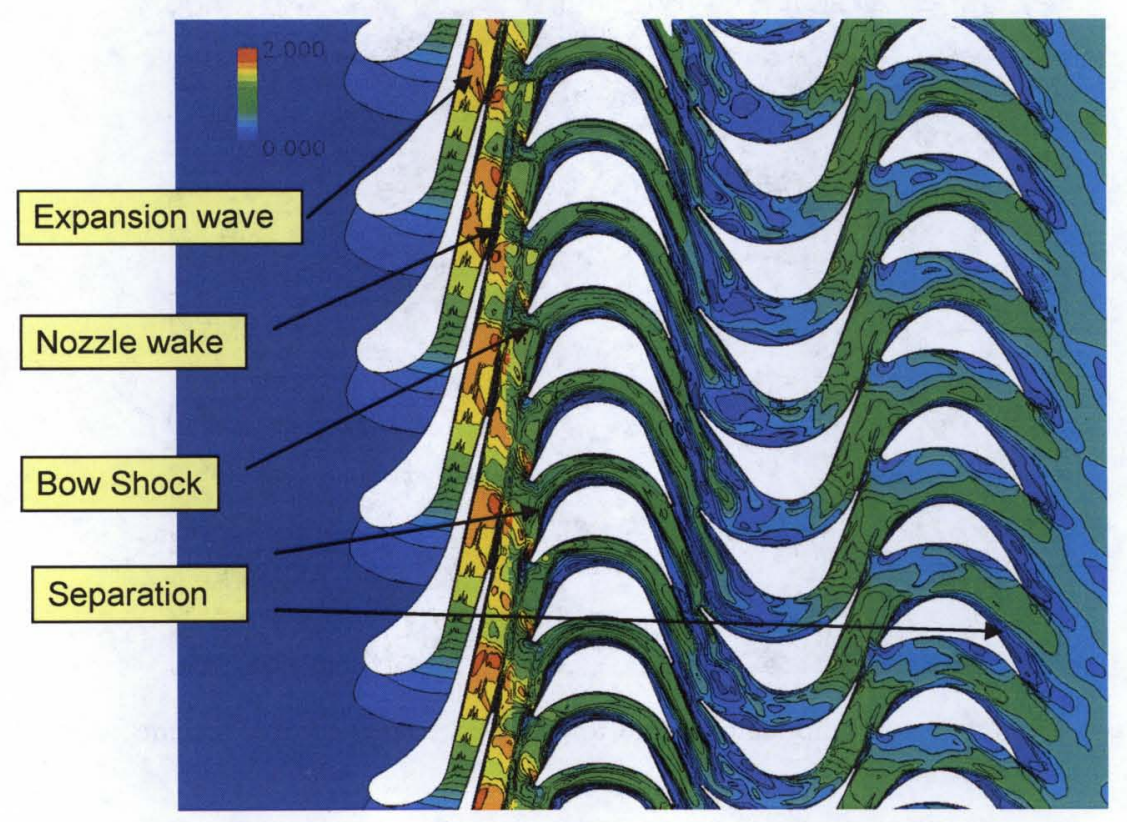

Figure 8. Relative frame Mach contours at midspan of the J-2X Mark72-F fuel turbine

Unsteady pressure envelopes for the J-2X fuel turbine are shown Figure 9 and Figure 10. The majority of the pressure drop in the turbine occurs across the nozzle as shown in Figure 9. The flow is choked at the throat of the

American Institute of Aeronautics and Astronautics 
nozzle, so the unsteadiness is confined to the uncovered portion of the suction surface and is caused by interactions with the rotor and the expansion wave from the adjacent nozzle. The greatest unsteadiness on the rotor occurs near the leading edge and is generated by several sources, including: a) passing wakes from the upstream nozzles, b) boundary layer separation induced by the bow shock of the adjacent rotor, and c) potential interactions with the upstream nozzles. Overall there is a slight pressure rise across the rotor near the hub and up through midspan.
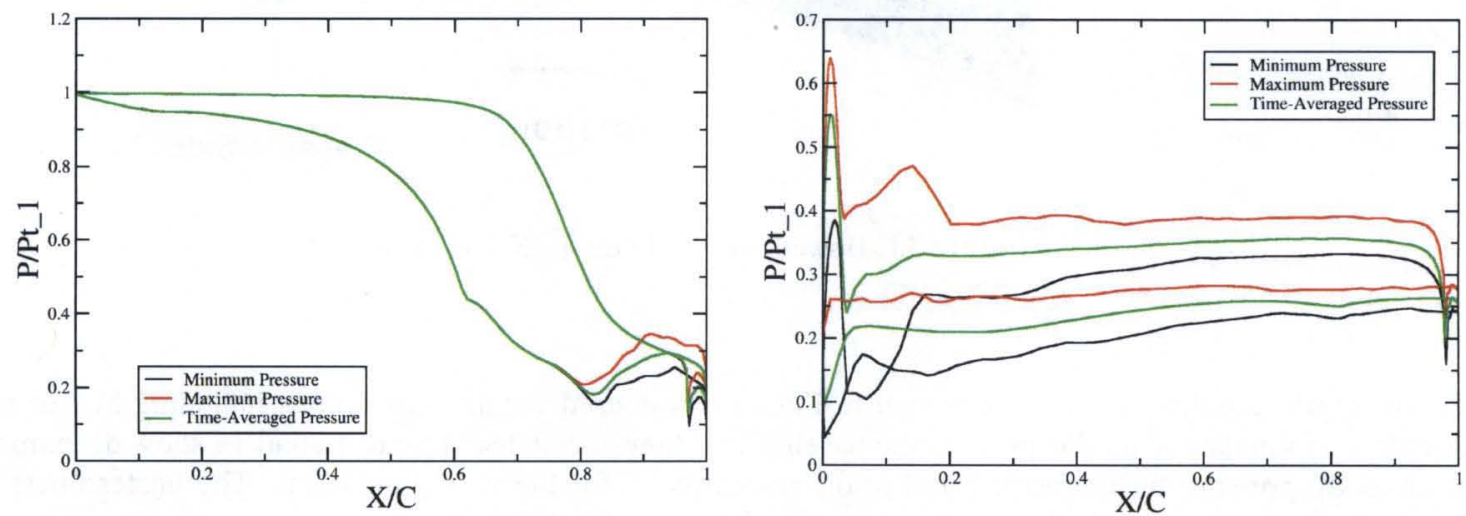

Figure 9. Midspan pressure envelope for the first stage of the J-2X fuel turbine. - nozzle on left,

The unsteady pressure envelopes on the second stage vane and rotor are shown in Figure 10. On the second stage vane the unsteadiness is generated by potential and wake interactions with the upstream and downstream rotors. A shock wave is evident at approximately $80 \%$ axial chord of the vane. A relatively large amount of unsteadiness is evident near the leading edge of the second stage rotor, and is caused by the wakes from the upstream vanes. Overall, there is little change in pressure across the second stage of the turbine.
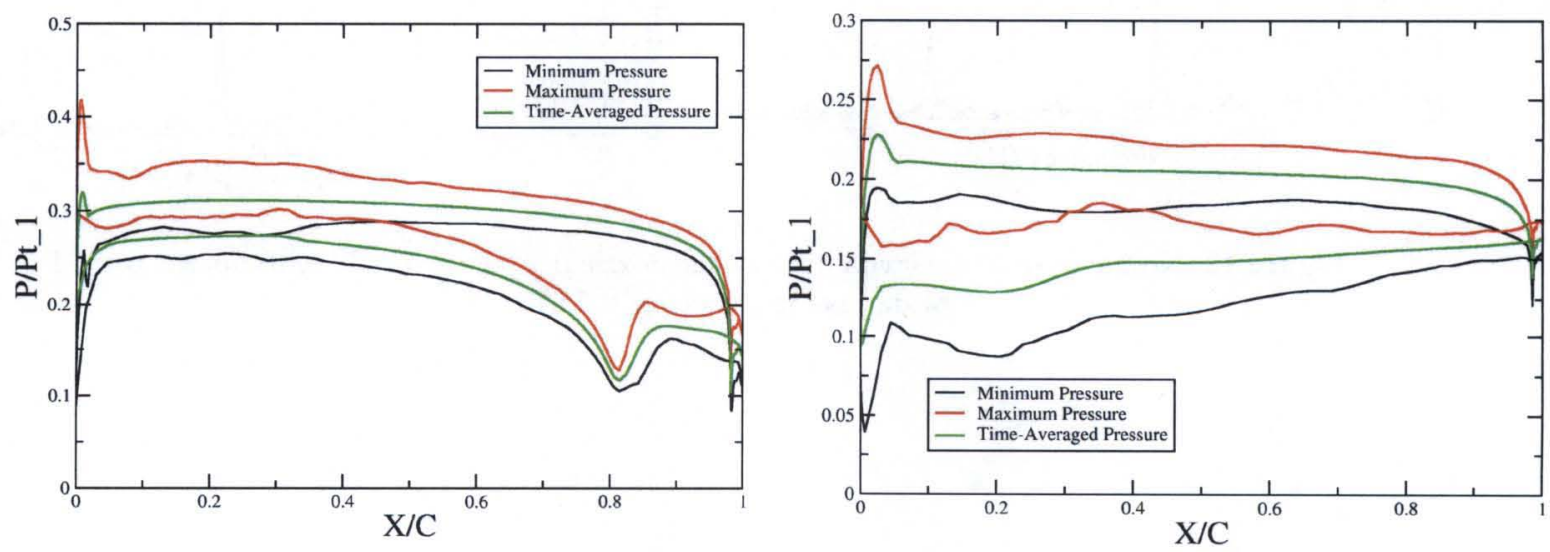

Figure 10. Midspan pressure envelope for the second stage of the J-2X fuel turbine. - vane on left, rotor on right. rotor on right.

Forced response analyses indicate high level of alternating stress for the $1^{\text {st }}$ vane $19^{\text {th }}$ mode in the baseline configuration. This mode is mainly a complex trailing edge mode excited by the interaction between the expansion waves at the vane trailing edge and the bow shocks at the blade leading edge. The $19^{\text {th }}$ mode could be eliminated from the operating range by bowing the vane - as shown in Figure 11 - and thus increasing its frequency by $15 \%$. 


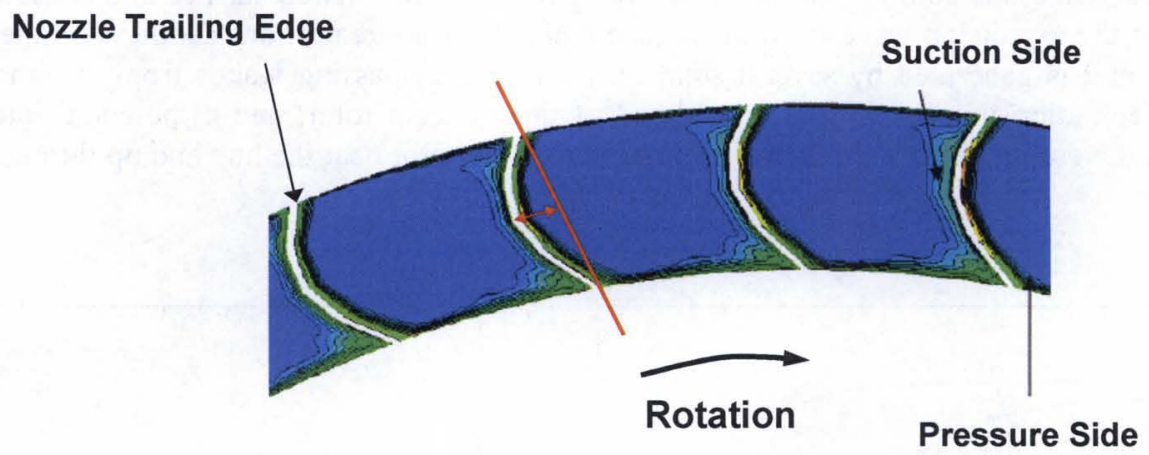

Figure 11. Bowed nozzles in the J-2X fuel turbine

The same grid topology as the one shown in Figure 6 was used for the simulations including bowed nozzles. The turbine performance is similar for both the baseline and bowed nozzles. Figure 12 and 14 show decompositions of the unsteady pressure on the nozzle and rotor, respectively, for the two simulations. The unsteadiness on the nozzle actually increases with the bowed nozzle, while the unsteadiness on the rotor decreases slightly.
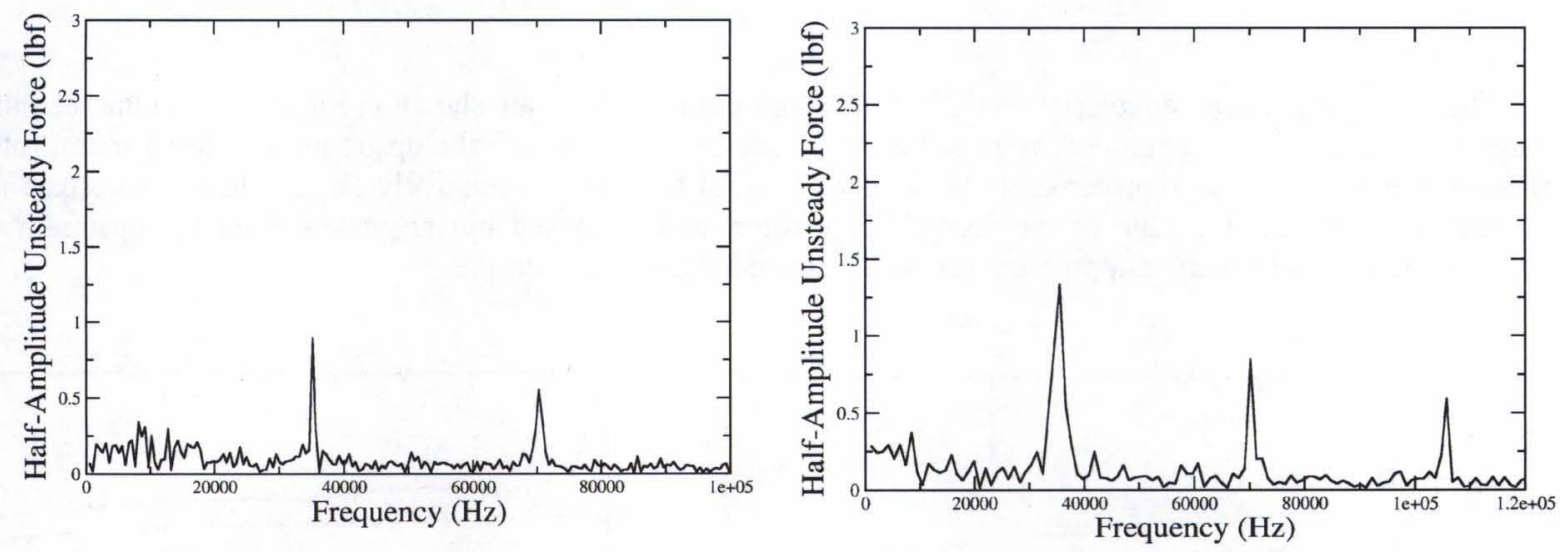

Figure 12. Nozzle unsteadiness with the baseline nozzle (left) and bowed (right) nozzle; rotor-1 blade passing frequency $=35,153 \mathrm{~Hz}$. 

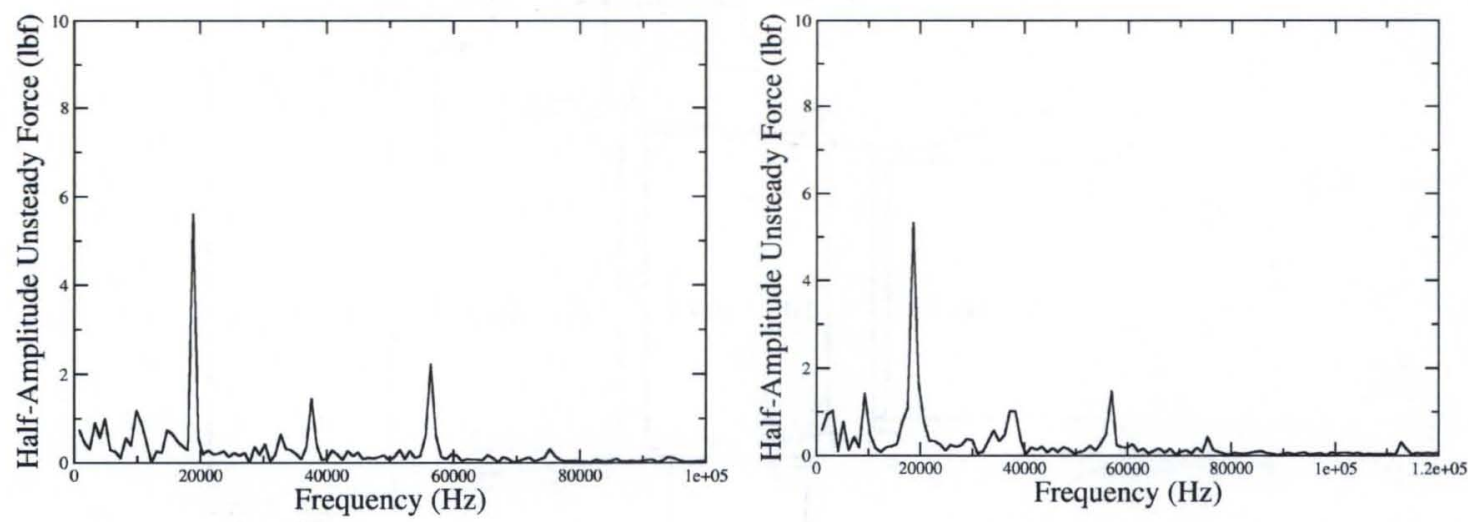

Figure 13. Rotor-1 unsteadiness with the baseline (left) and bowed (right) nozzle; nozzle blade passing frequency $=18,850 \mathrm{~Hz}$.

Subsequent structural analyses confirm the low level of stress for the $19^{\text {th }}$ mode, solving the problem for this specific mode. However, this technique of curving the vanes is not applied to the final design because the bowed vane alternating stress for the 7th mode is higher than that of the baseline design. Instead, additional mechanical damping is added to lower the vane trailing edge vibrations.

\section{The J-2X Oxidizer Turbine Mark72-O}

\section{A. General configuration}

The baseline configuration for the $\mathrm{J}-2 \mathrm{X}$ Mark72-O turbine is the heritage $\mathrm{J}-2$ oxidizer turbine design, also known under the Mark15-O denomination. The J-2 oxidizer turbine is a two stage impulse turbine which operates at lower pressure ratios than the fuel turbine, and for this reason, whereas the fluid velocity at the nozzle discharge is in the low supersonic range, the rotor inlet velocity in the relative frame of motion is subsonic.

Optimizations made on the $\mathrm{J}-2 \mathrm{X}$ engine cycle imposed an operating pressure ratio across the Mk72-O turbine lower than the J-2 engine cycle and consequently the flow regime at the Mark72-O nozzle discharge is subsonic. A summary of the turbine operating parameters for the same regime of operation is documented in Table 2 .

The new flow path design of the J-2X Mark 72-O turbine is shown in Figure 14. The turbine elements are identical to the heritage design with the exception of the $1^{\text {st }}$ nozzle vanes. Similar to the case of the Mark72-F turbine, the Mark72-O Campbell diagram indicates possible resonant interference at the $1^{\text {st }}$ stage rotor blades for the heritage configuration and as a design solution the number of nozzle vanes has been changed from 71 to 76 . 


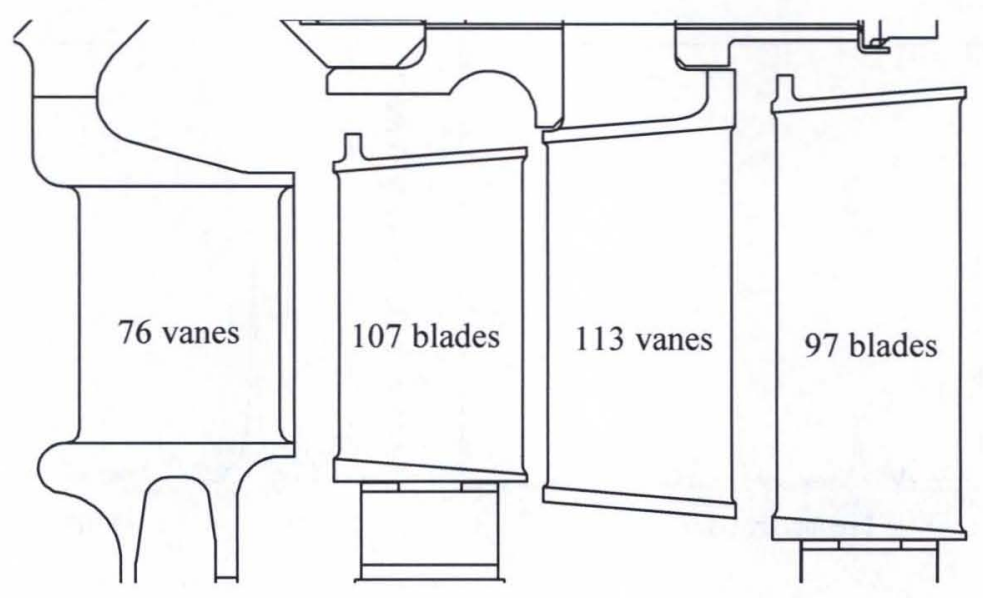

Figure 14. J-2X Mark72-O oxidizer turbine flow path.

Another specific concern for the Mark72-O turbine is related to the amount of axial thrust developed by the turbine. With a mean diameter of 15.5 inches, the turbine disks have significant area over which fluid pressure can exercise net thrust. A detailed study of the turbine configuration identified the pressure in the nozzle cavity area as critical in determining the value of the axial thrust. In turn, at given turbine operating boundary conditions, the main driver determining the pressure in the nozzle cavity area is the nozzle throat area. Consequently, following design notes found on 1960's documentation, detailed nozzle throat area measurements were made on heritage hardware. The measurements confirmed the notes which indicate that original J-2 Mark15-O production turbines had a throat area larger by approximately $1.0 \mathrm{in}^{2}$ than the blue print specification. The airfoils for the new row of 76 nozzles have been therefore designed with the same throat area as the baseline production hardware with proven flight performance. In addition to these precautions, detailed CFD analysis has been made for the flow in the turbine cavity areas, specifically addressing the axial thrust calculations.

$\begin{array}{ll}\text { Pressure ratio } & 2.00 \\ \text { RPM } & 11000 \\ \text { U/Co } & 0.173 \\ \text { Mean Diameter (in) } & 15.5\end{array}$

Table 2: 294K Ibf thrust operating point of the J-2X Mark72-O oxidizer turbine.

\section{B. J-2X Mark72-O turbine analyses}

The 3D Phantom code coupled with ANSYS finite element forced response analyses are employed to insure the reliability of turbine components similar to the Mark72-F analysis. The turbine has been modeled with the true blade ratios meaning, in this particular case of prime numbers of blades, a full $360^{\circ}$ CFD model comprised of around 58 million grid points. Figure 15 shows a section of the computational grid. The simulations were run on Altix clusters of 128 to 174 processors at the NASA Ames Advanced Supercomputing division (NAS) in Moffet Field, California. 


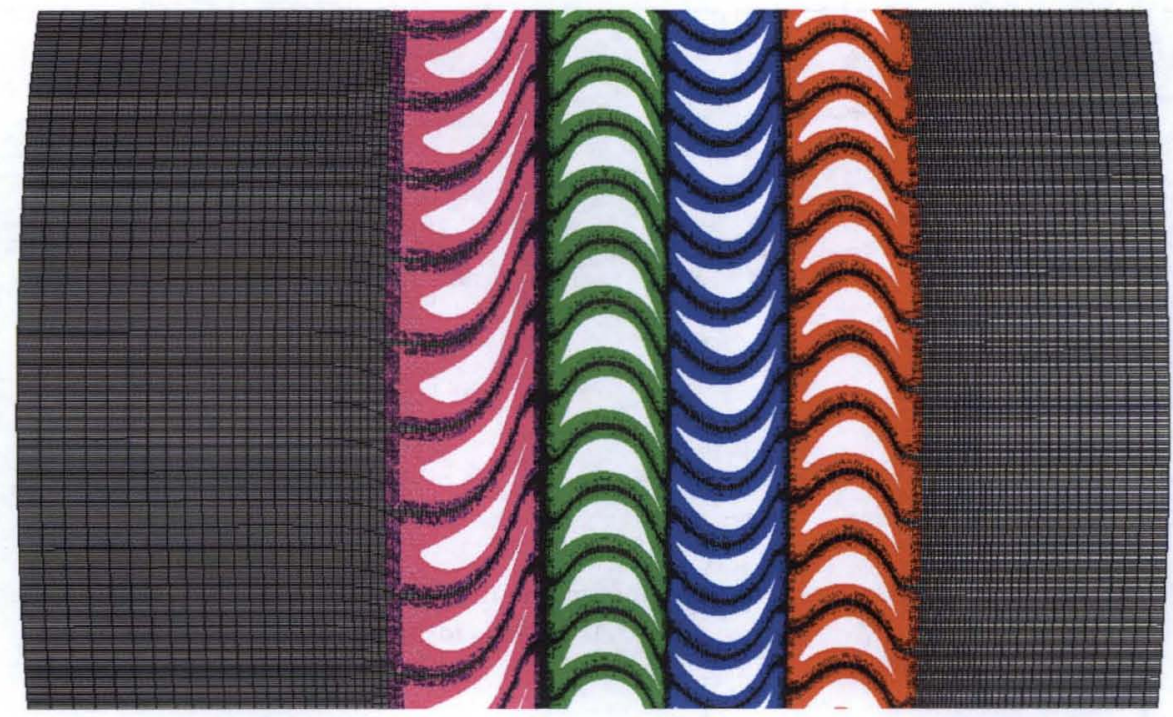

Figure 15. Computational grid for the J-2X Mark72-O oxidizer turbine

Figure 16 shows instantaneous static pressure and Mach contours at midspan of the turbine. Whereas the flow regime at the nozzle discharge has local transonic regions, the overall flow field remains subsonic. Weak vortex shedding can be also observed at the nozzle trailing edge.

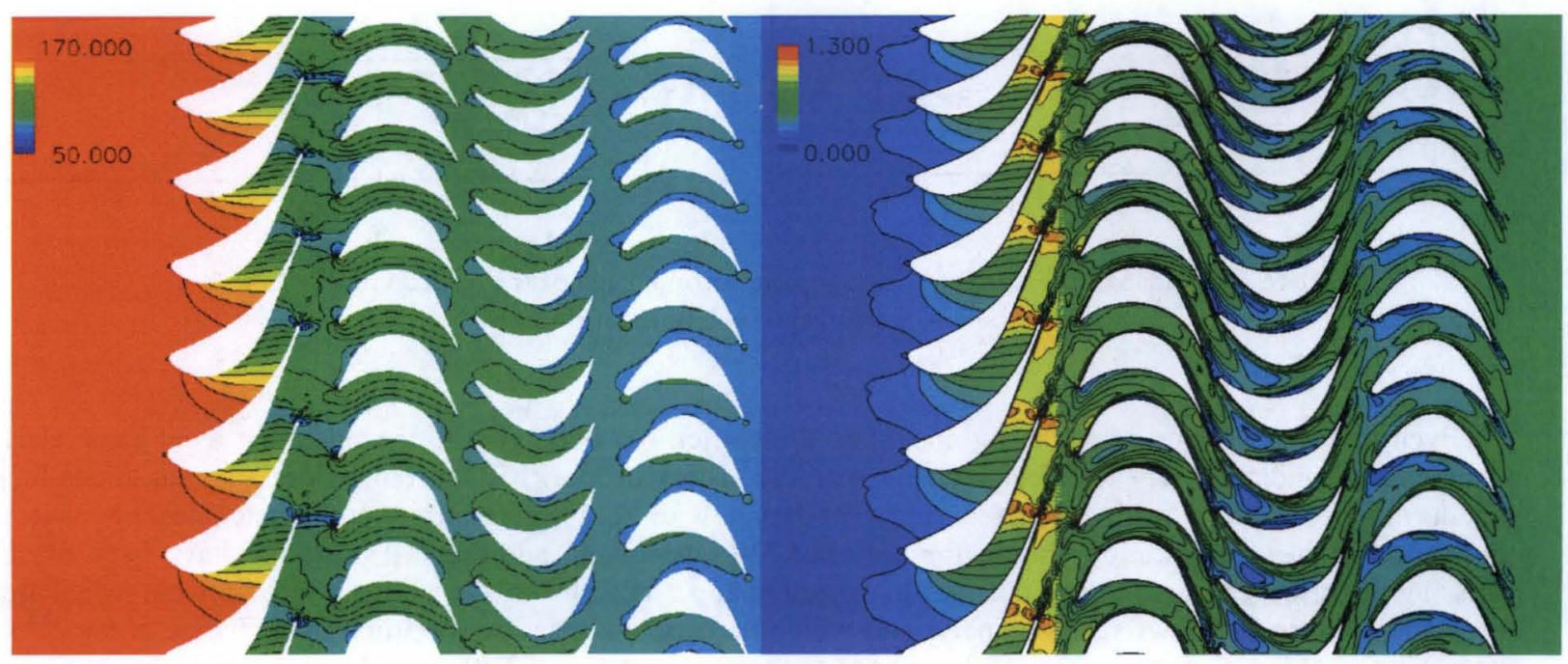

Figure 16. Static pressure (psi) and Mach values at midspan of the J-2X Mark72-O oxidizer

Unsteady pressure envelopes for the J-2X Mark72-O oxidizer turbine are shown in Figure 17 and Figure 18. The plots show benign operation without large extremes, smooth pressure contours and good loading on all rows. 

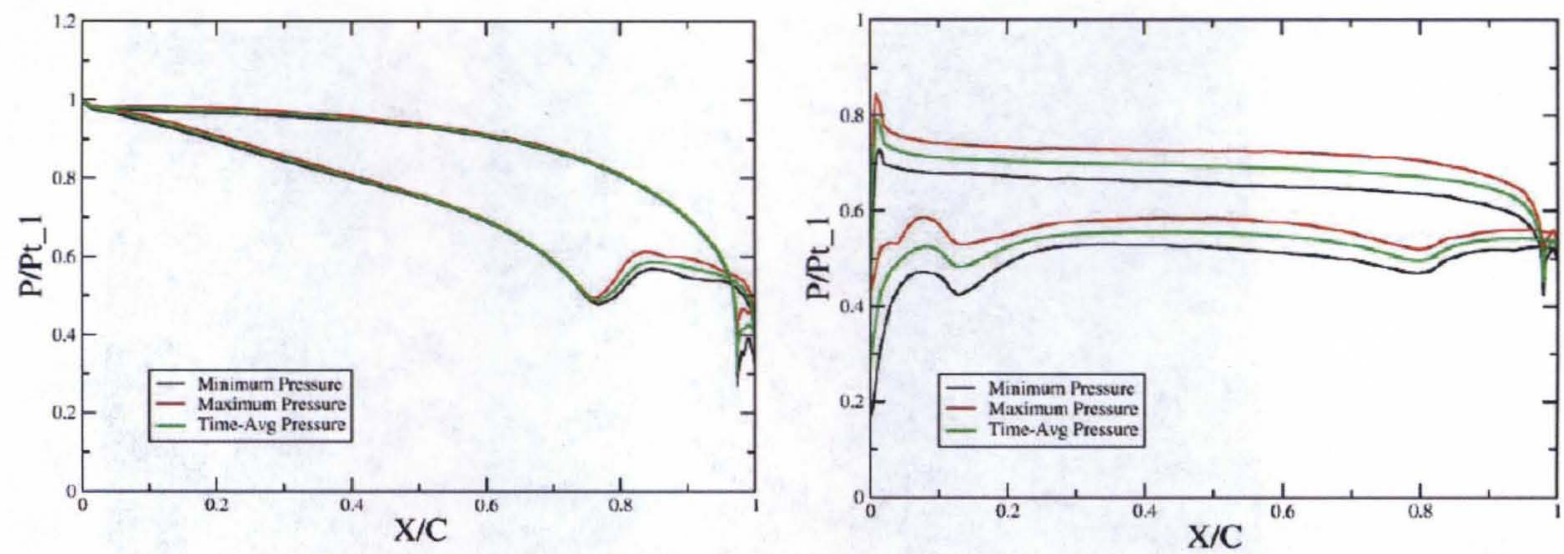

Figure 17. Midspan pressure envelope for the first stage of the J-2X Mark72-O oxidizer turbine. - nozzle on left, rotor on right.
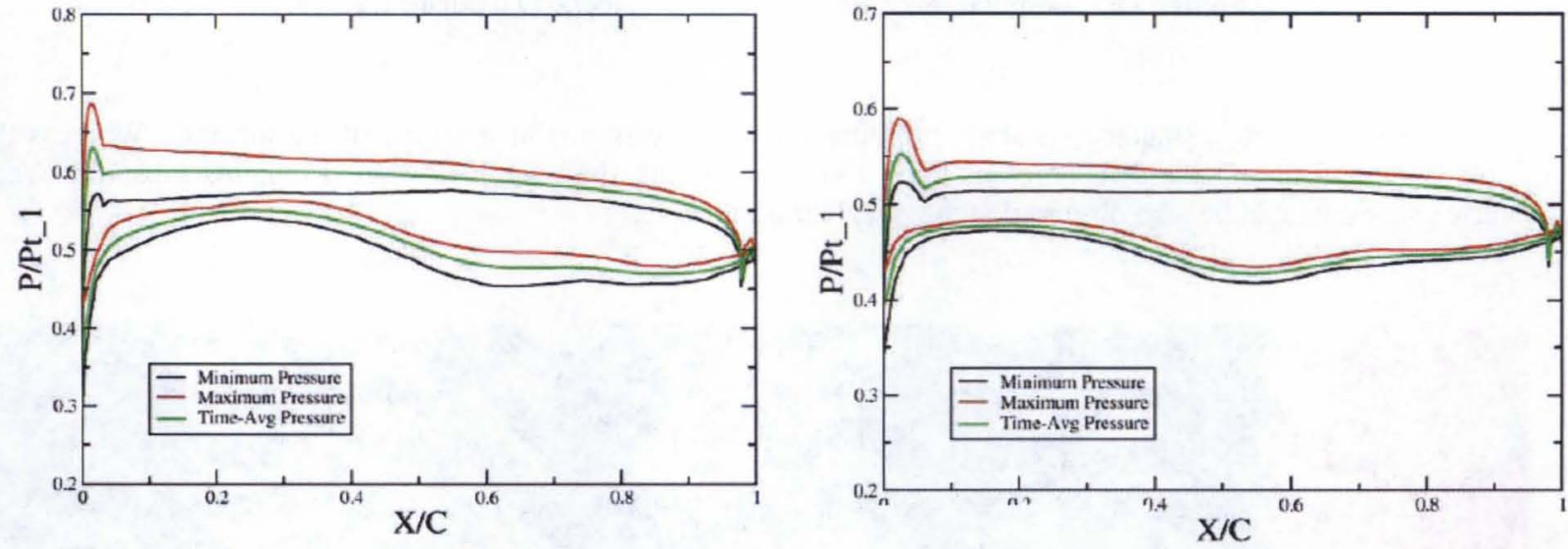

Figure 18. Midspan pressure envelope for the second stage of the J-2X Mark $72-\mathrm{O}$ oxidizer turbine. - stator vane on left, rotor on right.

Given the compact design of the turbine, special attention has been give to the operating axial gaps. Heritage documentation indicates repeated design changes on the history of Mark15-O turbine addressing variations in axial gap during operation. Stacking analysis and correlation with recently finalized power-pack testing have built confidence in the configuration chosen for the Mark72-O design. In addition, CFD studies have been made for assessing the effect of possible gap changes in operation and establish ways to mitigate those effects which are not acceptable. Figure 19 shows such an analysis in which the baseline gaps are modified by a change in the $2^{\text {nd }}$ stage stator vane axial location. The effect of the change is observable in the FFT plots of the unsteady force spectrum for the $2^{\text {nd }}$ stage rotor: the change in the gap value appears to amplify a low frequency band vibration which may interfere with one or more natural frequencies associated with lower modes of the rotor. As a result, a special assembly procedure has been conceptualized for the pump which ensures operating axial gaps at desired values. 

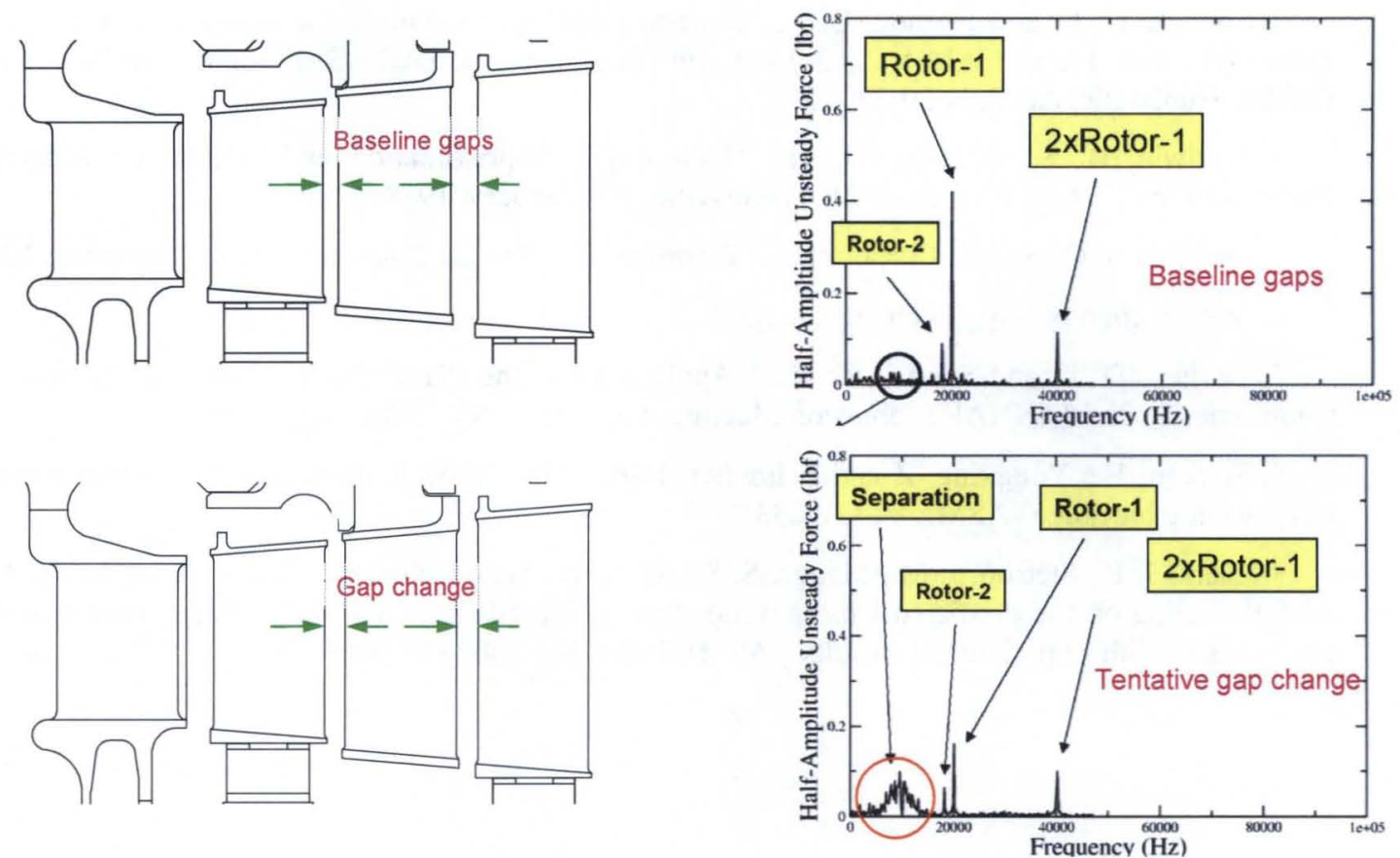

Figure 19. The effect of axial gap changes between $1^{\text {st }}$ stage rotor and $2^{\text {nd }}$ stage stator and $2^{\text {nd }}$ stage stator and rotor on the unsteady force spectrum for the $2^{\text {nd }}$ stage rotor.

\section{Conclusions}

The J-2X turbines which have been denoted as Mark72-F and Mark72-O for the fuel and oxidizer side, respectively, have been designed by preserving the flight proven heritage designs from the J-2 and J-2S engines. Pratt and Whitney Rocketdyne's (PWR) turbopump design team has applied robust and validated design processes while operating jointly with the NASA MSFC team in an efficient and synergistic manner. 3-D unsteady CFD results obtained by the MSFC team from Phantom CFD simulations run at the NAS center in Moffet Field, California have been analyzed for turbine performance verification by the PWR aerodynamic analysis team. The steady and unsteady pressure data from the CFD solution have been applied on the ANSYS structural models for stress and High Cycle Fatigue (HCF) analysis at PWR. The careful analysis has led to minimal design changes of the heritage design, specifically the turbine nozzles for both turbines have been redesigned. Various trades have addressed concerns related to airfoil HCF, axial thrust developed on the turbine and axial gap effects. The resulting designs for the Mark72-F and Mark72-O turbines are robust, safe, and performing per requirements set by the J-2X engine cycle.

\section{References}

1. W. Sack and J. Watanabe, "Development Progress of MB-XX Cryogenic Upper Stage Rocket Engine", 39th AIAA/ASME/SAE/ASEE Joint Propulsion Conference and Exhibit, Huntsville, Alabama, July 20-23, 2003, AIAA-2003-4486

2. Marcu, B., "Turbo-Pump Development and Test for the MB-XX Advanced Upper Stage Engine Demonstrator", 42nd AIAA/ASME/SAE/ASEE Joint Propulsion Conference and Exhibit, Sacramento, California, July 9-12, 2006, AIAA-2006-4380. 
3. Sondak, D. L. and Dorney, D. J., "General Equation Set Solver for Compressible and Incompressible Turbomachinery Flows," AIAA 2003-4420, 39th AIAA/ASME/SAE/ASEE Joint Propulsion Conference and Exhibit, Huntsville, AL, July 20-23, 2003.

4. Baldwin, B. S., and Lomax, H., "Thin Layer Approximation and Algebraic Model for Separated Turbulent Flow,'” AIAA Paper 78-257, Huntsville, AL, January, 1978.

5. Oefelein, J. C., Sandia Corporation, Livermore, CA, Private Communication, December, 2002.

6. http://webbook.nist.gov/chemistry/fluid

7. Dorney, D. J., and Sondak, D. L., “Application of the PHANTOM Analysis to Impeller and Diffuser Geometries," 52nd JANNAF Propulsion Meeting, Las Vegas, NV, May 10-13, 2004.

8. Starken, H., Yongxing, $\mathrm{Z}$ and Schreiber, H-A, "Mass flow limitation of supersonic blade rows due to leading edge blockage" ASME 84-GT-233

9. Clark, J. P., Stetson, J. M., Magge, S. S., Ni, R. H., Haldemann, C. W. and Dunn, M. G.: "The Effect of Airfoil Scaling on the Predicted Unsteady Loading on the Blade of a 1 and $1 / 2$ Stage Transonic Turbine and a Comparison with Experimental Results", ASME Paper No. 2000-GT-0446 